\title{
Géralde Nakam, Montaigne. La Manière et la Matière
}

\section{Sabine Lardon}

\section{(2) OpenEdition}

\section{Journals}

\section{Édition électronique}

URL : https://journals.openedition.org/studifrancesi/26152

DOI : 10.4000/studifrancesi.26152

ISSN : 2427-5856

\section{Éditeur}

Rosenberg \& Sellier

\section{Édition imprimée}

Date de publication : 1 avril 2007

Pagination : 166-167

ISSN : 0039-2944

\section{Référence électronique}

Sabine Lardon, « Géralde Nakam, Montaigne. La Manière et la Matière », Studi Francesi [En ligne], 151 (LI I I) | 2007, mis en ligne le 30 novembre 2015, consulté le 23 novembre 2021. URL : http://

journals.openedition.org/studifrancesi/26152 ; DOI : https://doi.org/10.4000/studifrancesi.26152

Ce document a été généré automatiquement le 23 novembre 2021.

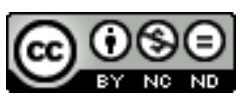

Studi Francesi è distribuita con Licenza Creative Commons Attribuzione - Non commerciale - Non opere derivate 4.0 Internazionale. 


\title{
Géralde Nakam, Montaigne. La Manière et la Matière
}

\author{
Sabine Lardon
}

\section{RÉFÉRENCE}

GÉRALDE NAKAM, Montaigne. La Manière et la Matière, nouvelle édition revue, corrigée et augmentée, Paris, Champion, 2006, p. 446 [1ère éd. épuisée: Paris, Klincksieck, 1992].

1 Par ce beau titre, G. Nakam se propose d'étudier le rapport étroit et permanent entre l'écriture «Maniériste» de Montaigne et sa pensée. Comme dans Le dernier Montaigne (Paris, Champion 2002), l'étude réunit des articles déjà parus auxquels s'ajoutent quatre chapitres inédits, ainsi que le précisent les «références d'origine» (pp. 441-443). L'auteur ne se contente pas toutefois de juxtaposer ces articles, mais les organise selon une structure en quatre sections. Si les chapitres s'enchaînent de manière parfois discontinue (comme ce chapitre I.3 sur la notion de passage au milieu de trois chapitres sur la santé et ses dérèglements, la construction du II ou encore le chapitre 17 qui aurait gagné à être placé après les chapitres 18 et 19), c'est que la cohérence du propos est à chercher plutôt dans la démarche. Démarche rigoureuse, qui amène G. Nakam à situer les questions abordées dans le contexte de l'époque à chaque fois que le sujet le nécessite avant de se concentrer sur les Essais, mais également à s'intéresser à la structure du livre (1580 et 1588) de manière macro- ou microstructurelle.

2 La première section «Genèse» regroupe cinq chapitres. Consacré au mythe du savoir, le chapitre 1 fait l'hypothèse d'un lien entre l'Académie de Musique et de Poésie créée par J-A Baïf en 1570 et reprise par Du Faur de Pibrac et le projet de Montaigne (la résiliation de sa charge au Parlement, le titre d'Essais, celui de certains chapitres de l'édition de 1580 et la structure polyphonique des chapitres). La comparaison toutefois entre quatre discours prononcés en 1576 à l'Académie sur le thème de la tristesse et le chapitre I.2 correspondant des Essais montre l'écart entre le discours académique et celui de Montaigne qui se serait orienté vers une démarche divergente dès 1572. Les chapitres 2 , 
4 et 5 observent le contraste entre dérèglement et santé dans les Essais à travers la question de la mélancolie et de la folie (ch. 2), du mal physique et de la santé (ch. 4) et de la démarche sceptique comme thérapeutique de la pensée (ch. 5), tandis que le chapitre 3 se consacre à la perception du temps et à la notion de passage chez Montaigne.

3 La seconde section, «Formes et figures», comporte cinq chapitres qui étudient respectivement: la métaphore antithétique de l'ombre et de la lumière dans le livre III (ch. 6); les deux figures de Julien l'Apostat (dans l'essai central I.19) et d'Alcibiade, ainsi que leurs points de rencontre (ch. 7); les lieux et les personnages vers lesquels Montaigne se projette en rêve (ch. 8); l'essai III.5 («Sur des vers de Virgile») dans lequel Montaigne fait, sans hypocrisie, le lien entre érotisme et poésie (ch. 9) et la question enfin du changement et du devenir (ch. 9).

4 La troisième section, «Le temps humain: l'action, l'histoire, le corps», se consacre tout d'abord au récit de deux épisodes politiques qui structurent l'essai I.24 posé en pendant de I.1 (ch. 11), puis aux traces, dans les Essais, des engagements et des refus politiques de Montaigne, fruits de son expérience de maire et qui amènent à rompre avec l'idée trop répandue d'un abstentionnisme politique de Montaigne (ch. 12). Nous regretterons ici le caractère purement allusif du terme «baroque» apparu dans le titre du chapitre «Trois principes de conduite politique. Renaissance et baroque» et repris uniquement en conclusion pour évoquer la «politique "baroque"» fondée «sur la méfiance et sur les calculs de la Raison d'Etat» (p. 227), sans que le terme ne soit défini dans ses rapports avec le Maniérisme par ailleurs évoqué. Le chapitre suivant prend pour base de réflexion deux exemples historiques des Essais choisis au hasard afin de montrer comment l'exemple soutient une réflexion comparative entre passé et présent (ch. 13). Les deux derniers chapitres sont consacrés au corps pour montrer comment Montaigne oppose la clarté et la justesse du langage du corps à celui de l'esprit dans les derniers essais (ch. 14) et fait de la nudité la garante d'une parole authentique (ch. 15).

La dernière section, «L'art et l'adieu», évoque les rapports entre l'écriture montaigniste et les arts à travers le motif de la main (ch. 16), la présence des beaux-arts (sculpture, architecture, arts décoratifs et ébénisterie) dans les Essais (ch. 18) et l'influence de la peinture sur Montaigne, «écrivain-portraitiste» (ch. 19). Trois autres chapitres se concentrent sur le livre III des Essais dont G. Nakam dégage une structure binaire en deux cycles de six chapitres (I-VI / VII-XII) parcourus par de nombreuses correspondances et conclus par le chapitre ultime (III.13), clé de voûte de l'ensemble. Cette structure trouve son sens dans un rapport accru entre l'écart temporel qui sépare Montaigne de ses contemporains et la coïncidence à soi-même (ch. 17), tandis que le second cycle se présente comme un adieu au monde (ch. 20). A part, l'essai III.13 se termine sur une citation votive d'Horace à Apollon dont G. Nakam dégage tous les enjeux (ch. 21).

Ceux qui chercheraient dans cet ouvrage une analyse de l'écriture maniériste de Montaigne seraient déçus: l'étude n'est pas stylistique. C'est que, comme l'indique le titre, la manière est ici indissociable de la matière. Sous la plume élégante de G. Nakam, ne s'en dégage pas moins, au fil des chapitres, la manière d'un Montaigne sensible au passage, aux oppositions binaires et aux effets de symétrie ou de rupture. 